\title{
Editorial
}

\section{Fabrice Duparc}

Published online: 27 December 2013

(C) Springer-Verlag France 2013

Dear colleagues,

2013 is over! It has been once more a great year for our journal Surgical and Radiologic Anatomy. The EACA and BACA Joint Congress has been a rich event in June in Lisbon, Portugal, with the participation of the Spanish and Brazilian Societies. Thanks to PR Antonio Goncalves-Ferreira and his team, the major topics of our field of activity have been explored, and a special symposium day has been devoted to the Education in Anatomy and to the place of the Institutes and Laboratories of Anatomy in the development of the Medical Training Centers. The number of participants and the quality of the scientific sessions reflect the actual increase of interest given to the research in Anatomy and Clinical Anatomy.

This has been also observed through the number of submitted manuscripts to SRA, more than 550 submissions were received within the year, coming from 46 countries all over the world. 1,310 reviewers were invited, 218 declined, and 739 completed the analysis. We are so grateful to them, their continued work allowed to propose to the authors a high level of quality in revisions, and to constantly major the scientific publishing in Anatomy.

In 2014, it will be my pleasure to share the Editorial responsibility with Dr. Bruno Grignon, MD-PhD, Anatomist and Radiologist (Nancy, France), who has been currently in charge of the "Medical Imaging" section since so many years, and who will become Associate Editor in Chief.

On behalf of the 27 Editors of our journal, I wish you a very nice and happy new year 2014. 